\title{
Application and Practice of Expressive Painting in Middle School Art Education
}

\author{
Wen Meng, Lei Cai* \\ Guangdong Polytechnic Normal University, Guangzhou 510665, Guangdong Province, China \\ *Corresponding author: Lei Cai, 503374643@qq.com
}

\begin{abstract}
By combing the theoretical framework of contemporary expressive painting and expressive art therapy, this study explores the application and practice of integrating expressive painting into middle school art education in hope to provide new ideas for art education and teaching in contemporary middle schools.
\end{abstract}

Keywords: Art education; Expressive painting; Art teaching application

Publication date: October 2021; Online publication: October 29, 2021

\section{Introduction}

Facing the drastic changes in art education, what are the different forms of art teaching? Could the particularity and healing of expressive painting be combined with the art curriculum standards? What enlightenment does the knowledge system constructed by expressive painting have for the current art education? In other words, in the face of the continuous innovation of art education and teaching, the significance of art education is not limited to painting skills. From the perspective of art function, art is used to express, convey, and edify. It can be traced back to the equal emphasis on rites by Confucius, music in ancient China, and the purification of the soul by Western art ${ }^{[1]}$. The issue is whether the psychological thinking of expressive painting can provide new and positive ideas for the task and goal of art education in the new era. Therefore, the thinking and methods of expressive painting are worth contemplating about by art educators, in order to create positive practical value for art education and teaching.

\section{Current psychological development of middle school students}

Compared with the general group, students are in a critical period of physical and mental development. The outbreak of the pandemic is more likely to have a complex and profound impact on their psychology. In the face of the situation, students still face many difficulties, so psychological adjustment is particularly important. Secondly, due to the rapid development of the times and personality factors, most groups have difficulties in emotional expression, in which they focus more on the emotion of fear of conflict, shame to express love or dissatisfaction, etc. In addition, the global spread of the COVID-19 does not only pose a threat to the safety of people's lives, but also lead to psychological changes. The outbreak of the pandemic is also more likely to have a complex and profound impact on the psychology of vulnerable and sensitive middle school students. Third, China is emphasizing more on aesthetic education. The art high school entrance examination, as a compulsory test for junior middle school students, is carried out all over the country, but its form and content have been questioned. For example, is there a specific inspection standard for art? As an educational content to improve students' aesthetics, could it be measured only in the form of examination? Could the natural advantages of art class still play a role? 
The content and methods of art education need to be improved, and the dilemma of difficult emotional expression also needs to be adjusted. Therefore, under the cultivation of the core literacy system, sharing the experience of expressive painting or facing the crisis of contemporary art educators, is a teaching design scheme that can be attempted. In order to explore the training mode of expressive painting with psychological thinking as well as character and image scanning literacy, emotional attitude and values should be in line with the reality of curriculum reform with certain practical significance in the postpandemic era.

\section{Practical significance of expressive painting to middle school students' mental health}

\subsection{Concept of expressive painting and its relevance to art education in middle schools}

\subsubsection{Concept of expressive painting}

Expressive art therapy (ETA) is a nonverbal technology. With creative, entertaining, symbolic, or metaphorical forms, it can convey information, relieve emotional disorders, promote communication, as well as stimulate, enrich, and expand psychological experience. Due to its colorful forms, from appearance to internal experiential intervention, it has the trend of dealing with emotional and psychological problems ${ }^{[2]}$. Examining the development of expressive art therapy is mainly influenced by psychoanalysts. This set of research methods can be traced back to the primitive society. Witch doctors and shamans use visual images and other elements to stimulate emotions, mobilize the body's immune ability, and promote the recovery from diseases. They engaged the psychosomatic relationship as the theme of psychotherapy and made full use of many artistic elements including visual image ${ }^{[3]}$. At the end of the 9th century, people began to try to systematically understand human beings through paintings. The initial research focused on children. The Art Education Research Center in East China Normal University carried out an experimental study on the promotion of teenagers' mental health through art education. Through research and practice, scholars concluded that art education is an effective way to promote teenagers' mental health and guide students to transform traumatic experience into profound art learning. Several research have explored the blending point of art education and expressive art, breaking through the view in the past that it is impossible for art teachers to play the role of expressive artists ${ }^{[2]}$. Therefore, research methods and thinking models of expressive painting have been constructed for reference and interpretation.

\subsubsection{Relationship between expressive painting and art education in middle schools}

Growing up, almost everyone has experienced various degrees of emotional trauma. After unfortunate experiences or changes in the family, some students begin to close up and change their personalities; thus, they are unable to live a normal life. Using art education to help students better express their emotions and grow in a healthier manner is an urgent problem that needs to be solved.

Although there are fundamental differences between art therapy and art education in essence, and it is difficult for art teachers without psychological background to play the role of art therapists, they have some similarities. First of all, both achieve the goal of self-realization and promote the development of sound personality through artistic activities. Second, trauma involves strong emotions and aesthetic experience, so the essence of artistic aesthetics may lead students into this field. Therefore, art teachers need to understand the impact of trauma as an aesthetic experience on students and guide students to relieve their psychological trauma through art learning ${ }^{[4]}$.

To sum up, the knowledge model of expressive art therapy has the possibility of teaching practice and research application for the study of art education, teaching, and the construction of diversified art teaching and training. 


\subsection{Requirements of promoting mental health in art curriculum standards}

The Art Curriculum Standards for Senior High Schools (Experiment), issued by the Ministry of Education, puts forward the clear goal of regulating psychological state as well as promoting physical and mental health. It points out that art is an emotional expressive activity, which allows people to gain a sense of achievement, alleviate and release tension, enhance people's mental health, as well as form a good physical and mental state along with social adaptability ${ }^{[5]}$. Although the discussion on students' psychological development described in the curriculum standard is relatively simple and not comprehensive, it generally puts forward the role of art education in promoting students' psychological development. Therefore, the educational goal of the school has been further clarified; that is, to give full play to the role of art education in cultivating sentiment and purifying the soul.

Under the guidance of the curriculum standard, the art education in schools has also undergone considerable development and diversified progress. For example, the creative activities of art teaching are richer, with new materials and more forms of expression. In addition, in the course of art appreciation, more excellent art works are highlighted. With the spirit conveyed through these art works and the way of expressing emotions through excellent works, students are encouraged to express emotions more intuitively through painting, shape healthy aesthetic interests, as well as meet the training requirements in terms of emotional attitudes and values. In addition, the renewal and application of art resources create a better teaching environment, encouraging students to reveal their traumatic experience to art learning, better experience the emotions in art works, and form a healthy psychology.

\section{Practice of expressive painting in middle school art education}

Nowadays, the relationship between teachers and students is not a one-way teaching but a two-way interaction. Such teaching does not terminate the relationship at the end of the course but establish supportive and trusting relationships between teachers and students after the end of the course. This study briefly explains the use of expressive painting in designing the art course in middle schools.

\subsection{Course description}

Design and application module of "Beauty of Face and Color" in Volume 2, Grade 7 of Ling-nan art textbook. This course mainly reflects different kinds of emotions through the expression of color. It belongs to the field of color composition, which highly involves expressive painting.

\subsection{Teaching objectives}

(1) Master the visual appreciation of color.

(2) Master the harmonious composition of face and color as well as the harmony method of color.

(3) The research scope includes visual factors, involving physiology, psychology, physics, art morphology, and other categories. It is the product of image thinking and logical thinking.

\subsection{Key and difficult points in teaching}

Allow students to learn the method of color harmony and the correct expression of color association as well as accurately use color association to express their emotions. 


\subsection{Teaching process}

\subsubsection{Classroom introduction}

Teachers would begin by asking the students, "If you use a color to express your current emotion, what color would you use and why?". In that manner, students would answer, and the teachers would summarize. Teachers would continue by showing color composition works and art works done by various famous artists to the students for appreciation and discussion. Then, a few representatives from the classroom would be asked to share the emotions felt through the art works. This would arouse the students' interest in learning.

\subsubsection{Classroom development}

(1) A plane is the trajectory of a line. Its shapes are different, which can be divided into geometric shape, organic shape, and accidental shape. They give people different feelings. Can you tell what are the different feelings?

(2) What different combination methods can two identical semicircles produce?

(3) How to use the design of basic shapes and bone lattices to form surface and color?

(4) Color harmony refers to the orderly and harmonious organization of two or more colors, exuding a pleasant feeling. The commonly used color reconciliation methods include area advantage reconciliation, complementary color mixing reconciliation, common color reconciliation, and color segmentation reconciliation.

(5) Color association refers to the practices and phenomena related to a certain color upon seeing that color, resulting in the exploration of a certain psychological state. For example, red can be associated with fire, blood, sun, enthusiasm, and vitality; green can be associated with grasslands, leaves, seedlings, peace, and growth. Then, ask the students to share the emotions that they can associate from the color, blue, and provide a summary.

\subsubsection{Summary}

Through this course, students' feelings toward colors are sublimated from a personal preference to a more scientific, broader, and universal realm of beauty, so as to cultivate their creative thinking and finally achieve the purpose of using colors flexibly as well as freely expressing colors and emotions.

\subsubsection{Assignment}

(1) Students are required to use different materials to express the composition of color and surface. They are required to include houses, trees, and people without any restrictions to other elements. The selected shapes and colors should be able to reflect their emotions. Then, they would have to write a paragraph that is consistent with their psychological feelings without any limit on the number of words.

(2) Students are required to apply the elements in the works done by famous artists to their designs for different items and ensure their designs are able to meet the function of "practicality, beauty, and economy."

This course design is different from the previous ones, which only require a single painting. Firstly, colors themselves have the effect of expressing emotions. Secondly, students would be able to express their emotions through the colors and contents (e.g., houses, trees, and people) used in their works as well as present them in the form of words. Teachers would be able to understand the students' overall psychological 
state and art learning state through feedbacks. The next step of teaching guidance and even psychological adjustment guidance can then be carried out. Students' aesthetic and art practice skills can also be improved through the appreciation and application of works done by professionals. In fulfilling the requirements of the curriculum standards and teaching materials, they play the role of cultivating sentiment as well as debugging and expressing emotions.

The above teaching design method reflects the close connection between expressive painting and art education. It does not only involve the learning of skills and the use of tools but it is a way to integrate the emotional expression and catharsis of expressive painting into the art learned by students, so as to inspire students to improve their attitudes and values as well as achieve the purpose of edification ${ }^{[6]}$.

\section{Conclusion}

All in all, the integration of expressive painting into art education creates a richer and in-depth communication bridge between teachers and students through various classroom teaching activities and interactions. It has a certain positive impact on both, students and art educators in a nonverbal way. Through art courses and works, there would be healthy psychological improvement among students. Art teachers can correct the teaching direction and constantly optimize teaching methods through students' expressive works. It is an idealized approach to promote students' all-round development.

\section{Disclosure statement}

The authors declare that there is no conflict of interest.

\section{Author contributions}

Lei Cai conceived the idea of the study. Wen Meng performed the experiments, analyzed the data, and wrote the paper.

\section{References}

[1] Chen C, 2002, Art and Humanistic Education (Volume I), Guiguan books, 2002 edition, 104.

[2] He C, 2017, Expressive Art Therapy 15 - A Good Medicine for Grief Counseling, Wu Nan books, 3.

[3] Zhang X, 2018, Summary of Expressive Art Research. Shanghai Research on Education, (2): 78-81.

[4] Qian C, 2007, Art Education Promotes Teenagers' Mental Health, Shanghai Culture Press, 43.

[5] Ministry of Education of the People's Republic of China, 2003, Art Curriculum Standards for Senior High Schools (Experiment), People's Education Press.

[6] Zhang Y, 2017, Practice and Application of Educational Biography in Communication Education. Journal of International Communication, (42). 